\title{
O campo da sexologia no Brasil: constituição e institucionalização*
}

| 'Jane A. Russo, ${ }^{2}$ Fabíola Rohden, ${ }^{3}$ Igor Torres, ${ }^{4}$ Livi Faro |

Resumo: Neste artigo apresentamos e discutimos os resultados parciais da investigação sobre a constituição do campo da sexologia contemporânea no Brasil, parte da pesquisa comparativa "Sexualidade, ciência e profissão na América Latina”. Uma segunda onda sexológica surgiu no Brasil em finais dos anos 1970 no Rio de Janeiro, com um viés essencialmente clínico, e em São Paulo, com um viés educacional. A década seguinte marcou um período de institucionalização no qual são criadas as duas associaçôes que hoje polarizam o campo em torno de uma sexologia mais eclética e multiprofissional e da chamada "medicina sexual", em geral dominada pelos urologistas. Discutimos os significados dessa polarização em termos das disputas profissionais subjacentes e das concepções de gênero implicadas em tais disputas.

Palavras-chave: sexualidade; gênero; sexologia; medicina sexual.

\author{
1 Doutora em Antropologia \\ Social, professora adjunta do \\ Instituto de Medicina Social da \\ UERJ; Coordenadora para o \\ Brasil do Centro Latino- \\ americano em Sexualidade e \\ Direitos Humanos/IMS/UERJ; \\ bolsista de produtividade em \\ pesquisa do CNPq. Endereço \\ eletrônico: jrusso@ims.uerj.br. \\ 2 Doutora em Antropologia \\ Social, professora adjunta do \\ Instituto de Medicina Social da \\ UERJ; pesquisadora do Centro \\ Latino-americano em \\ Sexualidade e Direitos \\ Humanos/IMS/UERJ; bolsista de \\ produtividade em pesquisa do \\ CNPq. Endereço eletrônico: \\ fabiola@ims.uerj.br. \\ 3 Mestre em Saúde Coletiva, \\ Instituto de Medicina Social da \\ UERJ; pesquisador do Centro \\ Latino-americano em \\ Sexualidade e Direitos \\ Humanos/IMS/UERJ. Endereço \\ eletrônico: \\ igortorres7@gmail.com. \\ 4 Mestre em Saúde Coletiva, \\ Instituto de Medicina Social da \\ UERJ; pesquisadora do Centro \\ Latino-americano em \\ Sexualidade e Direitos \\ Humanos/IMS/UERJ. Endereço \\ eletrônico: \\ livifaro@gmail.com.
}




\section{Introdução}

Este artigo tem como objetivo apresentar os resultados parciais de uma investigação em andamento sobre a constituição do campo da sexologia contemporânea no Brasil. A questão de fundo que buscamos examinar é a chamada medicalização / naturalização da sexualidade, apontada por diferentes autores como um fenômeno que vem se produzindo desde meados do século XIX. Temos como objetivo delinear a especificidade da medicalização / naturalização tal como se processa na atualidade, levando em conta que o que se chama "medicalização" envolve tanto controle social, quanto produção de identidades e de novas formas de subjetividade. Como objetivo mais amplo, que deverá ser contemplado no final da pesquisa, está a discussão crítica dos dilemas que cercam a sexualidade contemporânea - ora vista como um instinto incontornável e espontâneo, núcleo da liberdade do sujeito, ora como uma espécie de expertise adquirida através de treinamento e tecnologia.

O termo "sexologia" foi escolhido por ser uma designação tradicional de modos de intervenção e conhecimento que visam ao atendimento clínico ou à prevenção de distúrbios relacionados à sexualidade. Esta não é, entretanto, uma designação consensual dentro do campo. Há uma tendência atual a utilizar os termos "sexualidade humana", "saúde sexual", ou "medicina sexual", cada uma dessas expressōes indicando uma certa posição no conjunto de tensões e disputas que marcam o território em questão. $\mathrm{Na}$ verdade, o estudo das formas de autodesignação faz parte de nossa investigação. Optamos pelo termo "sexologia" por seu uso tradicional no decorrer do tempo. Mantemos, entretanto, a advertência de que, embora seja utilizado por atores e instituições do campo, o uso indiscriminado que dele fazemos é mais uma escolha metodológica do que uma realidade percebida no material pesquisado.

A investigação consistiu, até o momento, do levantamento de sites na internet (de clínicas, sociedades, associações, institutos), busca no site do CNPq e universidades, contatos telefônicos (para complementar dados levantados pela internet), levantamento e exame de três periódicos (Revista Brasileira de Sexualidade Humana, Revista Terapia Sexuale Revista Scientia Sexualis), entrevistas semiestruturadas com 15 profissionais relevantes do campo e observação participante em cinco congressos. ${ }^{1}$ A pesquisa foi conduzida dentro dos padrões éticos exigidos pela Comissão Nacional de Ética em Pesquisa / Conselho Nacional de Saúde / Ministério da Saúde (CONEP/CNS/MS), obedecendo ao disposto na Resolução CONEP no 196/96. 
Antes de passarmos à apresentação e análise dos dados já colhidos, faremos uma breve introdução ao surgimento da sexologia europeia nos primórdios do século passado, bem como das transformações que se seguiram ao processo de "transplantação" do novo campo de saber para os Estados Unidos, de modo a permitir uma compreensão da sexologia brasileira no contexto mais amplo do cenário sexológico internacional.

\section{Da "protossexologia" à sexologia contemporânea}

É possível falar que a sexologia, desde seu início no final do séxulo XIX, conheceu três "ondas" sucessivas. A primeira delas, chamada por André Béjin de "protossexologia”, 2 surgiu na passagem do século XIX ao XX na Europa e sobretudo na Alemanha. Através do discurso médico, tratava-se de construir uma racionalidade biológico/científica sobre as sexualidades periféricas ao casal e à família, contrapondo-se ao discurso legal ou religioso que tendia a criminalizá-las. A grande questão que movia os médicos dedicados à nova especialidade era a chamada "inversão" - como era então conhecida a homossexualidade. Neste momento, a medicalização da "inversão" era parte de uma luta política. Havelock Ellis e Magnus Hirshfeld, entre outros, faziam parte do movimento de "reforma sexual", que se concentrava na Alemanha, contra o código civil prussiano que criminalizava a chamada "sodomia". ${ }^{3}$ Ao mesmo tempo, a construção da perversão como objeto da medicina constituiu o personagem do perverso sexual, tendo como efeito transformar o que antes era um ato desviante, em identidade (FOUCAULT, 1977).

O manual do psiquiatra forense Richard von Krafft Ebing - Psycopatia sexualis ${ }^{4}$ - publicado em 1887, transformou-se em texto de referência acerca das perversões da sexualidade, conhecendo enorme sucesso de público. Segundo Harry Oosterhuis (1997), as cartas enviadas a Krafft Ebing no decorrer dos anos revelavam a felicidade e o alívio dos que se reconheciam nas categorias então descritas, e ofereciam ao psiquiatra-autor histórias de vida a serem incorporadas às novas versões do livro que iam sendo publicadas. Observamos, portanto, que a identidade forjada pela medicina - por se constituir contra a concepção propriamente criminal ou jurídica de atos passíveis de punição legal - não era de todo antipática aos sujeitos classificados como perversos.

Com o surgimento do nazismo e posterior eclosão da II Guerra Mundial, todo o movimento de reforma sexual alemão sofreu intensa repressão. Os grandes nomes 
da sexologia alemã foram obrigados a se exilar, bibliotecas e centros de informação foram destruídos. Desta forma, de modo semelhante ao que ocorreu com a psicanálise nesse mesmo período, a sexologia mudou-se para os Estados Unidos, e uma "segunda onda" sexológica - desta feita americana - surgiu no pós-guerra, mais especificamente nos anos 60/70 do século XX (IRVINE, 2005). Além da mudança geográfica, uma diferença importante vai distanciar os dois movimentos. No caso da primeira sexologia, como vimos, a medicalização da sexualidade não se opunha necessariamente à sua politização - ao contrário, os grandes sexólogos da época eram os responsáveis pelo movimento de "reforma sexual" que colocava em xeque o status quo. Nos anos 1960/70, marcados pela cada vez mais radical disjunção entre sexualidade e reprodução, as minorias sexuais vão buscar sua afirmação política contra o discurso médico. A segunda sexologia, que então surge, deixa de lado as antigas "perversões", que se transformam cada vez mais em uma questão de disputa política, passando a se debruçar sobre a sexualidade "normal”, voltando suas atenções e seu arsenal terapêutico para os casais heterossexuais.

Esta "segunda sexologia" tem nas pesquisas de Alfred Kinsey as bases sobre as quais se desenvolve. Foi Kinsey quem voltou seu interesse para a sexualidade do homem e da mulher "normais". Seus livros, publicados no final dos anos 40 (Sexual Behavior in the Human Male) e início da década de 50 (Sexual Behavior in the Human Female) conheceram um enorme sucesso. ${ }^{5}$ Colocando o tema da sexualidade na ordem do dia, trouxeram para o interior da conjugalidade heterossexual comportamentos antes vistos como transgressores ou anormais.

Ainda nos anos 1950, o médico ginecologista William Masters e a psicóloga Virginia Johnson deram início às suas investigaçôes sobre sexualidade na Washington University, em Saint Louis. Ambos realizaram pesquisas em laboratório com sujeitos humanos, de modo a observar e medir objetivamente o que vieram a chamar de "resposta sexual humana". Em 1966, publicaram o livro Human Sexual Response, e em 1970, Human Sexual Inadequacy. Neste último, considerado o marco da moderna sexologia, são listadas todas as perturbações possíveis da sexualidade de homens e mulheres e seu tratamento, constituindo-se na pedra de toque de uma especialidade emergente: o terapeuta sexual. Menos de cinco anos depois de sua publicação, já havia entre 3.500 e 5.000 centros de tratamento para problemas sexuais nos EUA (IRVINE, 2005). Nesse período surgiram diversos periódicos e sociedades científicas devotadas à sexologia nos Estados Unidos. O 
Archives of Sexual Behavior foi fundado em 1971, a International Academy of Sex Research e o Journal of sex and marital Therapy são de 1975. Em 1978 foi fundada a hoje poderosa World Association of Sexology ${ }^{6}$ (WAS).

Em 1998, o lançamento do citrato de sildenafil, conhecido comercialmente como Viagra, marcou uma nova transformação no campo da sexologia. Indicado para os casos de impotência masculina - rebatizada de "disfunção erétil" -, o Viagra surgiu como uma pílula mágica que colocou a farmacologia no centro das terapêuticas sexuais, e trouxe importantes reviravoltas na organização profissional do campo. Surge a terceira "onda" da sexologia.

A proposta de Masters e Johnson, posteriormente complementada pela de Helen Kaplan, ${ }^{7}$ envolve uma terapia psicológica, baseada na psicologia comportamental, e diz respeito sobretudo ao casal, que passa por uma espécie de "treinamento" para "aprender" a ter relaçôes sexuais prazerosas. Toda a literatura sexológica dos anos 70 e 80 se concentra basicamente nos problemas relativos ao casal. Há, em menor escala, trabalhos e pesquisas envolvendo homens, sendo a "disfunção erétil" o foco da maior parte desses trabalhos. ${ }^{8}$ Bem antes do Viagra, portanto, já se buscava algum tipo de tratamento médico para a impotência, fossem as injeções de papaverina ou as próteses penianas. O surgimento da "pílula mágica", entretanto, redimensionou todo o campo dos distúrbios sexuais, tendo como consequências importantes: o surgimento do urologista como ator relevante - senão dominante no campo profissional e científico, e uma tendência a focalizar no corpo do indivíduo problemas que antes poderiam ser interpretados de forma mais "relacional". Assistimos, portanto, a uma "re-medicalização" da sexualidade," e a um declínio de sua psicologização. Essas consequências, como veremos, terão implicações relevantes para as relações de gênero tanto no que diz respeito à reorganização profissional do campo, quanto no que tange ao modo mesmo de conceber o "transtorno" sexual.

\section{Anos 70: ginecologistas e psicólogos no Rio de Janeiro}

Embora tenha havido uma "primeira sexologia" brasileira no início do século XX (RUSSO; CARRARA, 2002), cujos principais expoentes foram José de Albuquerque e Hernani de Irajá, vamos tratar aqui da "segunda onda" sexológica, surgida já nas últimas décadas do século passado. Datando do início dos anos 70 do século XX, esta "segunda sexologia" coincidiu com o auge da chamada "cultura psicanalítica", 
que conquistava corações e mentes das camadas médias letradas nos grandes centros urbanos, e com o surgimento paralelo de uma cultura "alternativa", que implicou um revival das teorias de Wilhelm Reich. ${ }^{10}$

A década de 70 foi, no Brasil, um importante momento de transição política entre o período de maior obscurantismo e repressão da ditadura militar (a era Médici) e, a partir do governo Ernesto Geisel, que assumiu o poder em março de 1974, um período de distensão e tímida abertura política. ${ }^{11}$ Foi também um momento de intensa mobilidade social e simbólica para as camadas médias favorecidas pela política de concentração de renda do regime militar. Segundo Gilberto Velho, a conjuntura

reforçava o projeto individualizante de família nuclear com a ampla veiculação de uma propaganda que enfatizava o consumo e o sucesso material, fosse diretamente por parte do Estado, fosse por grandes empresas, do chamado "milagre brasileiro". É quando insistentemente se enfatiza e se constrói o modelo de família que compra, investe, viaja etc. Poder-se-ia dizer que é configurada com nitidez o que deveria ser uma família brasileira em uma sociedade capitalista moderna. (VELHO, 1981, p. 70).

Evidentemente, essa reconfiguração da família, se estava calcada em mudanças propriamente econômicas, implicou necessariamente transformações de mentalidade e valores. Como parte de tais transformações, já na segunda metade dos 70, os grandes centros urbanos assistiram ao florescimento da chamada "contracultura", que se difundiu entre os jovens filhos do "milagre econômico" (VELHO, 1998; HOLLANDA, 2004). Centrada em uma intensa revolução dos costumes, tinha como núcleo a chamada revolução sexual. É também nesse momento que um incipiente movimento de institucionalização reúne, no Rio de Janeiro, médicos e psicólogos em torno do projeto da constituição de um saber e de uma prática sexológica derivada do movimento norte-americano, ou seja, da proposta terapêutica de Masters e Johnson.

Já em fins dos anos 1960, um grupo de discussão sobre problemas ligados à ginecologia, chamado "Clube da Placenta", reunia-se regularmente, sob a liderança de Jean Claude Nahoum - médico ginecologista. Dele também participava o ginecologista Paulo Canella, ${ }^{12}$ além de outros médicos ligados ao Instituto de Ginecologia e Obstetrícia da Faculdade de Medicina da Universidade Federal do Rio de Janeiro (UFRJ). No final da década de 70, Geraldo Lana e Araguari Chalar 
Silva, psicólogos vinculados a uma clínica de atendimento em Terapia Comportamental - a Corpsi -, estimulados pela leitura dos trabalhos de Masters e Johnson, começaram a se interessar pelas propostas da terapia sexual. Em uma das reuniōes do Clube da Placenta, os dois grupos se aproximaram, formando o Núcleo de Sexologia da Sociedade de Ginecologia e Obstetrícia do Rio de Janeiro (SGORJ).

No início dos anos 80, articulados a profissionais de outras partes do país, os integrantes do núcleo da SGORJ fundaram a Comissão Nacional Especializada em Sexologia dentro da Federação Brasileira das Associações de Ginecologia e Obstetrícia (FEBRASGO). Dela participavam, do Rio de Janeiro, Jean-Claude Nahoum e Araguari Chalar Silva; de São Paulo, Nelson Vitielo; e de Brasília, Ricardo Cavalcanti (todos ginecologistas, com exceção de Araguari). Testemunhando um grau razoável de permeabilidade da ginecologia a olhares não-médicos, também integravam a comissão psicólogos e outros profissionais, como os educadores.

O movimento inicial para a estruturação do campo da (segunda) sexologia no Brasil foi, portanto, fruto da articulação entre a ginecologia-obstetrícia e a psicologia, cabendo de fato à ginecologia, como especialidade médica, fornecer a legitimação necessária para a nova especialidade. É necessário lembrar que, neste momento, a psicologia encontrava-se sob forte influência da psicanálise. A psicologia comportamental, que possui maior afinidade com a leitura sexológica que então surgia com os trabalhos de Masters e Johnson, era bastante marginal entre os profissionais da área.

A permeabilidade da ginecologia-obstetrícia à psicologia certamente tem a ver com a história dessa especialidade médica. Uma hipótese que podemos avançar é a provável afinidade entre o "objeto" da ginecologia-obstetrícia - a mulher - e uma leitura psicológica, ou pelo menos, não tão estritamente física dos males que a acometem. A relação entre os órgãos reprodutivos femininos e as afecções "nervosas" foi objeto de inúmeros estudos e intervenções no decorrer do século XIX e início do XX (ROHDEN, 2001). Nos anos 1960 e 1970, o movimento do "parto sem dor" já prenunciava a intensa transformação no modo de lidar com a gestação que surgiria nas décadas seguintes e que pode ser resumida pela ideia de "humanização" do parto e da gravidez. Tal transformação, embora possuísse uma vertente de forte crítica à medicina, também congregava uma espécie de vanguarda entre os médicos ginecologistas que buscava uma visão menos restrita aos aspectos puramente biomédicos na assistência à mulher. Imaginamos, portanto, que a ginecologia- 
obstetrícia, tendo, desde seus primórdios, lidado com processos "físico-morais" (caso da gravidez, parto e puerpério) pudesse, dentre as especialidades médicas, mais facilmente se articular com profissōes mais "morais" que "físicas", como a psicologia.

Entre 1983 e 1989, a Comissão Nacional Especializada em Sexologia da FEBRASGO organizou sete Encontros Nacionais de Sexologia, sendo o primeiro deles em São Paulo e o segundo no Rio de Janeiro. ${ }^{13}$ No Encontro de Gramado, em 1987, ocorreu a assembleia de fundação da Sociedade Brasileira de Estudos em Sexualidade Humana (SBRASH), sendo então eleita e empossada sua primeira diretoria. O Encontro do Rio de Janeiro, em 1989, transformou-se assim no I Congresso da SBRASH.

A SBRASH é já fruto de uma tensão que então começava a se instalar. A Comissão Nacional Especializada em Sexologia da FEBRASGO, que promoveu os primeiros encontros, começou a encontrar resistências dentro da Federação, pelo fato de abrigar em seus quadros profissionais não-médicos, como psicólogos e educadores. A fundação de uma sociedade multiprofissional foi a saída encontrada para a questão entre a subordinação à medicina e a autonomização da especialidade, que continuará a atravessar o campo.

Pela localização dos diversos encontros, é possível perceber que a sexologia contemporânea, em seus primórdios, se concentrou no sudeste e sul do país, regióes mais prósperas e desenvolvidas, com maior probabilidade de constituir um público consumidor para os novos serviços que então surgiam. Nesse percurso, não podemos deixar de mencionar a Sociedade Brasileira de Sexologia, fundada em meados dos anos 70, em Guarulhos (SP), num encontro entre médicos interessados no trabalho com sexualidade. Presidida pelo psiquiatra carioca Isaac Charan, a SBS, sociedade exclusivamente médica, foi responsável pela elaboração da Resolução no 1.019 / 1980 do Conselho Federal de Medicina, que estabelecia a sexologia como especialidade médica, e pela realização do XI Congresso Mundial de Sexologia no Rio de Janeiro, em 1993. No contexto atual, trata-se de uma sociedade sem grande expressão no campo, que parece estar desativada.

A institucionalização do campo através da SBRASH ocorre em meio a uma institucionalização acadêmica, no início ainda incipiente, com a criação de um curso de especialização em sexologia no Hospital Moncorvo Filho ${ }^{14}$ no início dos anos 80 e, posteriormente, a partir da mesma equipe e congregando novos nomes, do curso de pós-graduação lato sensu em sexualidade humana da 
Universidade Gama Filho (UGF). No movimento desses dois cursos de especialização, um sucedendo o outro, percebe-se que a relação entre a ginecologia-obstetrícia e a psicologia começa a se inverter. Embora os fundadores dos dois cursos façam parte das duas especialidades (ginecologistas e psicólogos), a passagem para a UGF foi realizada através da vinculação com o curso de psicologia, e não de medicina.

Duas observações podem ser feitas acerca desse fato. Em primeiro lugar, embora a ginecologia-obstetrícia oferecesse um "nicho" de maior legitimidade do que a psicologia comportamental no momento de constituição do campo, a medicina necessita demarcar fronteiras claras entre suas práticas e as de outros profissionais para manter sua própria legitimidade. Um alvo especial são os psicólogos, que já vinham disputando espaço com psiquiatras no que diz respeito à prática psicanalítica. Ou seja, a rivalidade entre as duas profissões já era antiga e dizia respeito justamente à pretensão dos psicólogos de se nomearem "terapeutas" e realizarem procedimentos considerados como prerrogativa dos médicos. Em segundo lugar, o acolhimento da sexologia pelos psicólogos da vertente comportamental, numa universidade particular não especialmente conceituada, indica que esta "segunda sexologia" se estrutura nas margens das especialidades e instituições de maior prestígio no meio profissional e acadêmico.

A pós-graduação lato sensu da Universidade Gama Filho deu origem a um mestrado em sexologia - o único do país - que funcionou de 1994 a 2005, com reconhecimento da Coordenação de Aperfeiçoamento de Pessoal de Nível Superior (CAPES) e mais de 100 dissertações defendidas. Tinha três áreas de concentração: sexologia clínica, sexologia educacional e sócio-sexologia, sendo a área de concentração em sexologia clínica reservada para médicos e psicólogos. Atraindo profissionais de diversas partes do Brasil, foi responsável por formar parte importante dos sexólogos em atuação no país.

\section{A certificação}

Logo após sua fundação, a SBRASH instituiu uma "Qualificação para o exercício da terapia sexual e educação sexual”. Vemos aí um movimento duplo. De um lado, a necessidade de chamar a si o controle da atribuição do título que designa a nova ocupação. De outro, em um movimento semelhante ao dos médicos, de separar a terapia da educação sexual. Ou seja, a multiprofissionalidade da associação 
não impede que os psicólogos se juntem aos médicos para monopolizar o título de terapeuta, diferenciando-o do de educador.

Em 2002, a Resolução no 1.634/2002 do Conselho Federal de Medicina revoga a Resolução CFM no 1.019/1980 e estabelece a sexologia não mais como especialidade médica, mas como área de atuação de ginecologia e obstetrícia e de urologia. ${ }^{15}$ Isso significa que, para um médico possuir certificado de área de atuação em sexologia, é necessário ser portador do título de especialista em urologia ou ginecologia e obstetrícia. Em uma nova resolução de 2003 (Resolução CFM no 1.634/2003), a sexologia aparece como área de atuação apenas da ginecologiaobstetrícia. A FEBRASGO é a responsável por realizar o concurso de habilitação na área de atuação de Sexologia em Ginecologia e Obstetrícia ${ }^{16}$. Não há concurso semelhante na Sociedade Brasileira de Urologia (SBU).

Nesse mesmo ano - 2003 -, a SBRASH, no lugar do antigo concurso de qualificação, passa a oferecer o Título de Especialista em Sexualidade Humana (TESH), concedido através de concurso ou da avaliação de diplomas de associados da SBRASH. O candidato pode requerer o título nas áreas de terapia sexual, educação sexual ou sócio-sexologia, sendo o primeiro título reservado a portadores do diploma de psicologia ou de medicina.

O curioso neste afã de controlar a atribuição de um determinado título é que em nenhum dos dois casos o controle é de fato exercido. Seja por falta de rigor do próprio órgão fiscalizador, seja por desinteresse dos potenciais detentores do título.

Através da listagem completa dos médicos do Brasil, disponibilizada no site do Conselho Federal de Medicina, constatamos que somente 17 profissionais possuem o título de especialista ou o certificado de atuação em sexologia. ${ }^{17}$ Além disso, médicos de outras especialidades (que não urologia ou ginecologia e obstetrícia), como psiquiatria, cardiologia, pediatria, endocrinologia e medicina do trabalho, também o possuem. No caso do TESH, a página web da SBRASH listava em 2005 somente 42 profissionais detentores do título, sendo 37 pela avaliação de diploma e cinco via concurso. ${ }^{18}$ Do total, 37 são especialistas em terapia sexual e cinco em educação sexual (quatro por avaliação de diploma e um por concurso) - número bastante reduzido quando sabemos que nesse momento a associação contava com mais de 200 associados.

Percebemos, portanto, que a ocupação é ainda pouco institucionalizada em termos de controle e monopólio do título. Ou seja, as instituições profissionais 
(seja o CFM, a FEBRASGO ou a SBRASH), elas mesmas em grau maior ou menor de institucionalização, disputam entre si um certo monopólio da titulação ou autorização dos profissionais, mas os próprios profissionais, aparentemente, prescindem dessa autorização. Uma hipótese plausível é que o título de psicólogo e, mais ainda, o de médico, possui legitimidade suficiente para prescindir de um outro tipo de titulação - sobretudo no caso de uma especialidade como a sexologia que, em seus primórdios, sofreu algum grau de estigmatização por parte do establishment médico (RUSSO; CARRARA, 2002). A falta de acordo quanto à própria nomeação do campo - sexologia versus sexualidade humana - diz respeito, acreditamos, a essa situação de uma especialidade potencialmente desacreditável. A substituição do termo "sexologia" pela expressão "sexualidade humana" e, mais recentemente, "medicina sexual", parece ser justamente uma tentativa de, a partir de uma nova designação, distanciar-se do estigma potencial herdado dos primeiros tempos da sexologia.

\section{São Paulo e os urologistas}

Em São Paulo, a "segunda sexologia" parece ter surgido num período um pouco posterior ao surgimento do movimento carioca. No início dos anos 80 , duas sexólogas bastante conhecidas trabalhavam (oferecendo treinamento e cursos mais voltados para a área de educação sexual) no Instituto Sedes Sapientiae - instituição de grande prestígio no campo "psi” local, e conhecida por abrigar saberes e profissionais localizados fora do mainstream intelectual mais tradicional. Uma delas, Marta Suplicy, ${ }^{19}$ tornou-se referência nacional ao apresentar um programa de TV (TV Mulher) na rede de televisão de maior audiência do país, em que temas ligados à sexualidade, à educação sexual, à saúde da mulher eram discutidos diariamente. Em pleno regime militar, Marta falava no ar sobre orgasmo feminino e usava a palavra vagina, o que gerou diversos protestos. Em 1987, fundou o Grupo de Trabalho e Pesquisa em Orientação Sexual (GTPOS), uma ONG que desenvolve até hoje projetos de educação sexual em escolas da cidade de São Paulo. Feminista, entrou para a política partidária. ${ }^{20}$ Atualmente afastada do campo, foi fundamental para a popularização do termo "sexóloga".

Em 1984, foi fundado o Instituo H. Ellis - Centro de Medicina Reprodutiva e Sexualidade. ${ }^{21}$ Apesar de ter sido fundado por um urologista, percebemos que a sexualidade feminina, e com ela a ginecologia, estão colocadas em cena, na medida em que a instituição tem na medicina reprodutiva um dos seus focos principais. 
Em dezembro de 1987, em um curso sobre impotência organizado pelo $\mathrm{H}$. Ellis, um grupo de médicos, sob a liderança do fundador do próprio instituto, criou a ABEI - Associação Brasileira para o Estudo da Impotência - uma associação que, com o tempo, tornou-se a principal divulgadora no país do que hoje é chamado de "medicina sexual", congregando em seus quadros sobretudo urologistas. A ABEI foi fundada com o objetivo de trazer para o Brasil, em 1990, o IV World Meeting on Impotence, organizado pela International Society for Impotence Research (ISIR). Até 2000 funcionou como uma instituição fechada, isto é, o núcleo inicial podia convidar novos membros, mas a associação não era aberta à adesão voluntária de outros profissionais do campo. Seguindo um movimento mundial de abandonar o termo "impotência", 22 carregado de conotaçôes negativas, a ABEI transformou-se, no ano de 2003, em ABEIS - Associação Brasileira para o Estudo das Inadequações Sexuais. Apesar de também congregar psicólogos em seus quadros, permanece com um nítido predomínio de médicos.

Comparada com a SBRASH, portanto, sua orientação é claramente médica, e sua associação com o Departamento de Andrologia da SBU (Sociedade Brasileira de Urologia) aparece em parcerias como nas "Jornadas de sexualidade" realizadas em várias cidades brasileiras. Na página web da Associação vemos, por exemplo, o seguinte anúncio: " $31^{\circ}$ Congresso Brasileiro de Urologia. 20 anos de existência da ABEIS. Para este marco do pensamento científico da sexualidade brasileira, teremos um Simpósio de Sexualidade e $\mathrm{DAEM}^{23} \mathrm{em}$ parceria com o Departamento de Andrologia da SBU. Agende-se.” Na mesma página, os logotipos de quatro laboratórios farmacêuticos (Lilly, Pfizer, Schering e Medley) aparecem com destaque. ${ }^{24}$ Todos são fabricantes de medicamentos contra a "disfunção erétil".

Chegamos, portanto, na terceira "onda" da sexologia, que pode ser chamada de "medicamentalização" da sexualidade. Um terceiro profissional entra em cena: o urologista, praticamente tomando o lugar do ginecologista-obstetra. E o homem, com suas disfunçôes, substitui a mulher (e o casal) como cliente preferencial. Além da "disfunção erétil", doença que, como vimos, se associa intimamente ao surgimento dos medicamentos orais para a antiga impotência, assiste-se ao surgimento de outra importante disfunção masculina, a Deficiência Androgênica no Envelhecimento Masculino, a chamada DAEM. Neste caso, de modo semelhante ao que ocorreu com a menopausa feminina, constroem-se os contornos 
e as características de uma "andropausa" (marcada pela deficiência de androgênio), o que provavelmente levará à mesma "solução" encontrada para a menopausa: a reposição hormonal. Percebe-se aí um novo passo na medicalização da velhice, que deixa cada vez mais de ser vista como uma fase da vida, transformando-se em "deficiência" a ser sanada pela medicina. Os limites (e a expectativa) de uma vida sexual plena (e saudável) tendem a se estender indefinidamente.

A ABEIS, segundo nos parece, permanece à margem da querela psicólogos versus médicos. Embora tenha psicólogos em seus quadros e mesmo como membros da diretoria, e embora psicólogos frequentem suas jornadas, a superioridade hierárquica da medicina e de suas práticas (em especial a liberdade para prescrever remédios) fica muito clara em seus boletins e nos eventos que divulga e promove. Ao mesmo tempo, a questão da certificação perde relevância, já que o diploma de médico faz com que o profissional possa prescindir de qualquer outro título. Assistimos, portanto, a uma certa polaridade entre a SBRASH (mais multiprofissional) e a ABEIS (mais médica), que, por sua vez, recobre a antiga tensão entre psicólogos e médicos. Essas duas polaridades relacionam-se não apenas a um certo modo de conceber as "disfunções sexuais" mas também à diferença de gênero. Os médicos costumam ser homens em sua maioria (em geral urologistas) e se ocupam das disfunções masculinas. Estas, mais físicas do que morais, têm sua importância destacada no universo médico.

É importante assinalar que a relação entre as duas associações (e as duas possíveis vertentes da sexologia clínica - uma mais multiprofissional e outra mais nitidamente médica), apesar de aparentemente muito cordial, não é de simetria. A SBRASH abre espaço em seus congressos para palestras e "aulas" de urologistas da ABEIS, mas o contrário geralmente não acontece. $\mathrm{O}$ mesmo se pode dizer do site da ABEIS, que não indica a SBRASH como link relevante.

Os congressos da SBRASH reúnem um público muito grande e diversificado, havendo presença expressiva de profissionais da área de educação e mesmo de estudantes de psicologia e áreas afins. Há uma tendência à dispersão de temas, que tendem a abranger tanto temáticas mais claramente vinculadas à prática clínica, quanto temas ligados à orientação / educação sexual, a HIV/Aids, à saúde pública e mesmo à diversidade e direitos sexuais. Essa extensa abrangência, se por um lado é responsável pelo grande sucesso de público dos encontros, por outro não atrai um público mais qualificado. Os laboratórios farmacêuticos parecem já ter percebido 
isso, pois entre os congressos de 2003, 2005 e 2007 houve nítido declínio na presença e no financiamento da indústria.

A abrangência do temário dos congressos da SBRASH oculta outra tensão presente no campo: entre os clínicos e os educadores. Estes últimos parecem constituir uma parte considerável do público consumidor dos congressos e encontros observados. Entretanto, os temas mais voltados para a clínica ocupam majoritariamente os horários nobres das conferências e mesas-redondas, enquanto os temas que discutem educação ou prevenção tendem a ocupar os espaços reservados para os "temas livres", menos valorizados na estrutura dos congressos. Aí são encontrados pontos de vista mais políticos e engajados, associados, muitas vezes, aos grandes temas da saúde pública.

Entre os cinco núcleos de pesquisa e ensino sobre sexualidade ${ }^{25}$ ancorados em universidades públicas, quatro são voltados para a temática da educação sexual, sendo que, destes, pelo menos três também estão cadastrados como grupos de pesquisa no CNPq. Ou seja, a educação sexual, apesar de ocupar posição subordinada no campo, obteve um grau maior de legitimidade acadêmica quando comparado com a vertente clínica. Sua proximidade de leituras divergentes e politizadas da sexualidade também a distancia do campo clínico e pode aproximála do terreno ocupado por ativistas e movimentos sociais. ${ }^{26}$

\section{Conclusões preliminares}

Nossa pesquisa, ainda em curso, revelou que o campo da sexologia contemporânea brasileira $^{27}$ constituiu-se e firmou-se institucionalmente nos anos 80 do século passado. Os anos 90 assistiram ao surgimento de várias instituições de formação ou atendimento clínico, de cursos de pós-graduação lato sens $u^{28}$ e de alguns grupos de pesquisa em universidades públicas. O desenvolvimento dessas instituições e grupos, apesar de ter-se iniciado no Rio de Janeiro, consolidou-se majoritariamente em São Paulo (cidade e estado) e, de modo geral, no sudeste do país (com exceçôes na Bahia e em Brasília). Após um surgimento vinculado à ginecologia e à psicologia, a chamada medicina sexual parece estar se impondo como vertente dominante do campo. Ao mesmo tempo verificamos, sobretudo a partir da observação participante nos congressos e encontros, que não é possível falar de duas posições antagônicas que se opõem de forma sistemática, mas sim de um continuum. 
Para compreendermos esse continuum e seguindo as pistas do material pesquisado, propomos, para fins analíticos, uma distinção em três áreas de atuação: a medicina sexual (a mais próxima da biomedicina), a sexologia clínica (que se articula tanto com a biomedicina quanto com a psicologia) e a sexologia educacional. A medicina sexual seria, portanto, um dos polos do nosso continuum. Mesmo ela, porém, apresenta certo grau de flexibilidade, possuindo uma vertente mais radical, vinculada explicitamente à indústria farmacêutica, e outra mais soft, que se comunica com a sexologia clínica. Esta, por sua vez, em sua vertente mais medicalizada, se submete aos ditames científicos e clínicos da medicina sexual, tendendo a se aproximar de uma visão multidisciplinar em sua vertente mais psicológica. Quanto mais se distancia da visão estritamente médica, mais se aproxima da sexologia educacional, havendo sobreposição entre as duas áreas de especialização, sendo comum encontrar profissionais que se dedicam tanto à clínica das disfunções quanto à orientação de professores, adolescentes e crianças. No caso da sexologia educacional, encontramos de novo um continuum que vai desde a referida sobreposição com setores da sexologia clínica, até a associação a visões mais políticas e ativistas da sexualidade. As fronteiras, de todo modo, não são fixas nem rigidamente demarcadas; ao contrário, são porosas, e permitem combinações e articulações entre posiçôes que, em outros contextos, podem se colocar como antagônicas.

Segundo Pierre Bourdieu (apud RUSSO, 1993), todo grupo profissional funciona potencialmente como um campo ou como um corpo. O funcionamento de uma dada ocupação profissional enquanto campo significa dispersão, conflito ou mesmo contradição. A necessidade de se demarcar com relação a ocupações vizinhas faz com que o campo passe a funcionar como um corpo. Surge então uma tendência a limitar os conflitos e guardar a unidade, enfatizando os interesses gerais da ocupação sobre as definições antagônicas (constituindo o que se costuma chamar esprit de corps). A constituição de um corpo é inseparável da imposição do que Bourdieu chama de numerus clausus, isto é da definição do direito de entrada no corpo ou dos limites do pertencimento àquela profissão ou ocupação.

Pode-se perceber, a partir do modo como se estrutura a sexologia enquanto profissão em nosso país, que os partidários da medicina sexual - em sua maioria urologistas - tendem a pressionar o que até então tem funcionado como campo a se transformar num corpo com regras mais ou menos claras de entrada e pertencimento (no caso, a posse de um diploma de medicina). Em contraposição 
a essa tentativa de faire corps, colocam-se não apenas os psicólogos, mas também médicos de outras especialidades, favorecendo uma concepção mais eclética do papel e das atividades a serem exercidas pelo sexólogo, mantendo não apenas a dispersão em termos de definição do campo, mas também, o que é mais fundamental, uma certa dispersão em termos da definição de quem pode fazer parte do campo. Daí a possibilidade de uma aliança com educadores e outros profissionais, aliança esta sempre sujeita a revisão quando se trata da atividade clínica stricto sensu.

Evidentemente, tais disputas e alianças não se dão apenas no campo das ideias e de posições mais ou menos medicalizantes, mas se articulam fortemente ao poder de definição da indústria farmacêutica. Esse poder diz respeito, é claro, ao direcionamento das pesquisas através do seu financiamento, mas também à promessa do respaldo científico - porque embasado no funcionamento concreto e mensurável do corpo - que deverá substituir a tendência mais "intuitiva” e menos "objetiva”, seja da psicologia ou da clínica médica menos atravessada pela tecnologia. Ou seja, se o ganho financeiro é a parte mais visível da história, o ganho simbólico é perceptível no estilo de se apresentar, nas comunicaçôes feitas nos congressos, nos slides repletos de detalhes anatômicos ou de tabelas. Assim, através de sua "farmacologização", o sexo torna-se algo objetivo, concreto, mensurável. E, de preferência, masculino. As disfunçōes femininas, apesar da tentativa de enquadrálas no mesmo esquema anatômico-estatístico, parecem menos afeitas à objetivação. Deste modo a sexologia, no seu afã de tornar-se científica, parece corroborar, com suas novas práticas e novos conhecimentos, a velha dualidade que aproxima o masculino da objetividade e da visibilidade, e o feminino da subjetividade e de uma misteriosa invisibilidade. ${ }^{29}$

\section{Referências}

BÉJIN, André. Crepúsculo dos psicanalistas, manhã dos sexólogos. In: ARIÉS, P.; BÉJIN, A. (Org.). Sexualidades ocidentais. 3 ed. São Paulo: Brasiliense, 1987.

BULLOUGH, V. Science in the bedroom: a history of sex research. New York: Basic Books, 1994. FARO, L. As disfunçôes sexuais femininas no periódico Archives of Sexual Behavior. Dissertação (Mestrado em Saúde Coletiva) - Instituto de Medicina Social, Universidade do Estado do Rio de Janeiro, Rio de Janeiro, 2008.

FOUCAULT, M. História da Sexualidade I: a vontade de saber. Rio de Janeiro: Graal, 1977. 
GIAMI, A. Sexual health: the emergence, development and diversity of a concept. Annual Review of Sex Research, v. XIII, 2000.

. Fonction sexuelle masculine et sexualité féminine. Permanence des représentations du genre en sexologie et en medecine sexuelle. Paris: Seuil, 2007 (Communications: corps et techniques, 81).

HOLLANDA, H. B. Impressões de viagem: CPC, vanguarda e desbunde 1960/70. 5 ed. Rio de Janeiro: Aeroplano, 2004.

IRVINE, J. Disorders of desire: sexuality and gender in modern sexology. Philadelphia: Temple University Press, 2005.

OOSTERHUIS, H. Richard von Krafft-Ebing's "step children of nature”: psychiatry and the making of homosexuality. In: ROSÁRIO, V. (Org.). Science and Homosexuality. New York: Routledge, 1997. ROHDEN, F. Uma ciência da diferença: sexo e gênero na medicina da mulher. Rio de Janeiro: Fiocruz, 2001.

RUSSO, J. A.; CARRARA, S. L. A Psicanálise e a sexologia no Rio de Janeiro de entreguerras: entre a ciência e a auto-ajuda. História, Ciência e Saúde-Manguinhos, Rio de Janeiro, 2002, v. 9, n. 2, p. 273-290.

RUSSO, J. A. O corpo contra a palavra. Rio de Janeiro: UFRJ, 1993.

VELHO, G. Individualismo e cultura. Rio de Janeiro: Zahar, 1981.

VELHO, G. Nobres e anjos, um estudo de tóxicos e hierarquia. Rio de Janeiro: Jorge Zahar Editor, $1975 / 2005$.

WEEKS, J. Sexuality and its discontents: meanings, myths and modern sexualities. 4 ed. London: Rougledge \& Kegan Paul, 1995.

\section{Notas}

* Este artigo apresenta resultados da pesquisa "Sexualidade, Ciência e Profissão no Brasil”, que integra a pesquisa comparativa "Sexualidade, Ciência e Profissão na América Latina", coordenada pelo Centro Latino-americano em Sexualidade e Direitos Humanos - CLAM/IMS/UERJ, em parceria com o INSERM (Institut National de la Santé et de la Recherche Médicale), que envolve a participação de investigadores de outros cinco países da região, a saber, Argentina, Chile, Colômbia, México e Peru.

${ }^{1}$ Os congressos em que estivemos presentes, realizando trabalho de campo, foram o VIII Congresso Brasileiro sobre Inadequações Sexuais, o IX, X e XI Congresso Brasileiro de Sexualidade Humana; e o XIII Congresso Latino Americano de Sexologia e Educação Sexual.

${ }^{2}$ Em seu já clássico artigo "Crepúsculo dos psicanalistas e manhã dos sexólogos” (BÉJIN, 1987).

${ }^{3}$ A Liga Mundial para Reforma Sexual foi fundada em 1921, durante a Conferência Internacional para Reforma Sexual baseada na Ciência Sexual, realizada em Berlim, sob a liderança de Magnus Hirschfeld. 
No início dos anos 30, havia na Alemanha cerca de 80 organizações pela reforma sexual, congregando mais de 350 mil pessoas (cf. BULLOUGH, 1994).

${ }^{4} \mathrm{O}$ título completo em inglês da edição de 1890 é Psychopatia Sexualis with Especial Reference to Contrary Sexual Instinct: a legal medical study.

${ }^{5}$ Sexual Behavior in the Human Male vendeu 200 mil exemplares nos dois primeiros meses após sua publicação (WEEKS, 1995, p. 77).

${ }^{6}$ Em 2006, mudou seu nome para World Association for Sexual Health. Sobre a emergência do termo "saúde sexual", ver Giami (2000).

${ }^{7}$ Terapeuta sexual americana, redefiniu o ciclo da resposta sexual humana proposto por Masters e Johnson, incluindo a fase do desejo.

${ }^{8}$ Ver sobre isso o levantamento realizado por Faro (2008) no Archives of Sexual Behavior.

${ }^{9}$ Consideramos aqui que a primeira sexologia era francamente médica. O movimento liderado por Masters e Johnson tendeu a aproximá-la da psicologia. Neste sentido o que aqui chamamos de terceira "onda sexológica" implicou uma reaproximação com a leitura biomédica stricto sensu.

${ }^{10}$ Psicanalista dissidente, Reich propunha uma interpretação corporal dos males psicológicos, que deveriam por isso ser tratados no e pelo corpo. Foi um dos arautos da chamada "revolução sexual", por considerar que o objetivo de toda terapia é a recuperação da "potência orgástica" do indivíduo.

${ }^{11}$ Essa abertura "lenta gradual e progressiva" vai se consolidar na década seguinte, com a anistia aos políticos banidos e perseguidos pelo regime e a eleição indireta pela câmara dos deputados, em 1985, de um presidente civil do partido de oposição.

${ }^{12}$ Eleito presidente da SBRASH (Sociedade Brasileira de Estudos em Sexualidade Humana) para o biênio 2007-2009.

${ }^{13}$ Os encontros seguintes realizaram-se em Belo Horizonte (1985), Curitiba (1986), Gramado (1987), e novamente em São Paulo (1988).

${ }^{14}$ Sede do Instituto de Ginecologia e Obstetrícia da Universidade Federal do Rio de Janeiro.

${ }^{15}$ Segundo o anexo I desta mesma resolução, uma área de atuação é "uma modalidade de organização do trabalho médico, exercida por profissionais capacitados para exercer açōes médicas específicas, sendo derivada e relacionada com uma ou mais especialidades".

${ }^{16}$ Informação obtida através do coordenador das áreas de atuação da FEBRASGO em 2005.

${ }^{17}$ Disponível em: http://www.portalmedico.org.br/novoportal/index5.asp, acesso em 29/10/2008.

${ }^{18}$ Em buscas realizadas na página da SBRASH em 2008, não foi possível localizar a lista dos profissionais que possuem o TESH.

${ }^{19}$ A outra sexóloga a que nos referimos é Maria Helena Matarazzo, socióloga com mestrado em educação sexual nos Estados Unidos. 
${ }^{20}$ Marta Suplicy foi também deputada federal (1995-1998), prefeita da cidade de São Paulo (20012005), ministra do Turismo do governo Luis Inácio Lula da Silva (2006-2008) e de novo candidata à prefeitura de São Paulo em 2008.

${ }^{21}$ Disponível em http://www.instituto-h-ellis.com.br/pacaembu/institucional.asp, acesso em 28/4/ 2008.

${ }^{22}$ No decorrer dos anos 80, o termo "impotência" foi sendo substituído pela expressão "disfunção erétil”, hoje em dia largamente difundida. Ver, sobre isso, o texto de Alain Giami neste volume.

${ }^{23}$ Sigla para "Deficiência Androgênica no Envelhecimento Masculino".

${ }^{24}$ Disponível em: http://www.abeis.com.br, acesso em: 10/08/2007.

${ }^{25} \mathrm{Na}$ verdade encontramos um número maior de grupos de pesquisa cuja temática é a sexualidade. Em nosso levantamento, entretanto, consideramos somente os que se inserem no campo sexológico propriamente dito (ver a introdução deste artigo).

${ }^{26}$ Esta vertente do campo sexológico apareceu menos nos dados coletados até agora, e deverá ser objeto de maior atenção no decorrer da pesquisa.

${ }^{27}$ Abrangendo o que chamamos de "segunda e terceira ondas sexológicas".

${ }^{28}$ Em nosso levantamento, constatamos a proliferação, possivelmente datando do final dos anos 80, de cursos de aperfeiçoamento, especialização e atualização em sexologia (ou sexualidade humana), dirigidos a públicos variados (médicos, psicólogos e educadores, basicamente) em todo o Brasil, com maior concentração em São Paulo. Em 2005, contamos 102 cursos de especialização/aperfeiçoamento em sexologia e/ou sexualidade humana oferecidos a diferentes profissionais em clínicas, institutos, ONGs e até em universidades reconhecidas do país.

${ }^{29}$ Sobre a permanência das representações de gênero na sexologia, ver Giami (2007). 


\section{Abstract}

\section{The field of sexology in Brazil: constitution and institutionalization}

In this paper we present and discuss the preliminary results of an investigation on the constitution of the contemporary field of sexology in Brazil, which is part of the comparative research "Sexuality, science and profession in Latin America". A second sexology arose in Brazil in the late 70's in Rio de Janeiro, with an essentially clinical approach, and in São Paulo, with an educational approach. The following decade brought a period of institutionalization in which the two associations that nowadays dominate the sexological field were created. They represent the two main trends in modern sexology; a more eclectic and multiprofessional approach and the so-called "sexual medicine", dominated by urologists. We discuss the meanings of this polarization in terms of its underlying professional disputes and the gender assumptions implied in such disputes.

Key words: sexuality; gender; sexology; sexual medicine. 